\title{
MAPA DE EMPATIA PARA OS ESTUDOS DE USUÁRIOS DA INFORMAÇÃO: PROPOSTA DE ABORDAGEM INTERDISCIPLINAR
}

\author{
ANA CLARA CÂNDIDO* \\ PATRÍCIA SOARES DA SILVA BERTOTTI*
}

\begin{abstract}
RESUMO
O objetivo deste estudoé apresentar o instrumento "Mapa de Empatia" como proposta complementar às análises e aos métodos consolidados para os estudos de usuários da informação. Trata-se de um instrumento constituído em gestão \& negócios e que tem despertado interesse para outros contextos de aplicação. O potencial do Mapa de Empatia em aplicações de estudos de usuários está na compreensão do seu comportamento e de suas necessidades. É um estudo exploratório, que reúne conceitos de áreas distintas para obtenção de soluções complementares. A análise desta aplicação elucida o ponto de vista do usuário da informação, representado por estudantes que desempenharam atividades de estágio nestas unidades de informação, com o intuito de fornecer diferentes perspectivas. Estas foram verificadas a partir do olhar sobre as necessidades e desejos dos usuários e potenciais usuários, como forma de subsidiar potenciais novas ações e serviços.
\end{abstract}

PALAVRAS-CHAVE: Estudos de Usuários; Mapa de Empatia; Perfis de usuários.

\section{MAP OF EMPATHY FOR STUDIES OF INFORMATION USERS: PROPOSED INTERDISCIPLINARY APPROACH}

\begin{abstract}
The aimsare to present the 'Empathy Map' instrument as a complementary proposal to the analyzes and the consolidated methods for the studies of information users. It is a consolidated instrument in management $\&$ business and has attracted interest in other contexts of application. The potential of Empathy Map in user study applications lies in understanding their behavior and needs. It is an exploratory study,
\end{abstract}

* Doutora em Avaliação de Tecnologia - Universidade Nova de Lisboa. Atualmente é professora no Departamento de Ciência da Informação da Universidade Federal de Santa Catarina e Pesquisadora Associada no Centro Interidisciplinar de Ciências Sociais da Universidade Nova de Lisboa (CICS.NOVA). E-mail: acc.anaclara@gmail.com

Graduanda em Arquivologia pela Universidade Federal de Santa Catarina, integrante do grupo de pesquisa em Gestão Estratégica da Informação, Empreendedorismo e Inovação. E-mail: <patricia.bertotti@outlook.com> 
gathering concepts from different areas to obtain complementary solutions. The analysis elucidates the point of view of the information user, represented by students who perform internship activities in these information units in order to provide different perspectives from the needs and desires of users and potential users, as a way to subsidize potential new actions and services.

KEYWORDS: User studies; Empathy Map; User Profiles.

\section{INTRODUÇÃO}

Os desenvolvimentos recentes no âmbito das Tecnologias de Informação e Comunicação (TICs) proporcionaram inúmeras alterações no ambiente das unidades de informação e, consequentemente, trouxeram mais dinamismo na introdução de novos serviços de interação com o usuário. Este cenário de mudanças fez com que a unidade de informação recorresse a novos métodos e instrumentos de gestão para a implementação de novos processos e melhorias nos processos existentes.

Neste sentido, ao longo dos últimos anos, foram realizados relevantes trabalhos que trouxeram reflexões sobre a evolução dos estudos de usuários no âmbito das unidades de informação, bem como o perfil de comportamento destes usuários em diversos contextos. (FIGUEIREDO, 1994; WILSON, 2000; BAPTISTA; CUNHA, 2007; GASQUE; COSTA, 2010; COSTA; RAMALHO, 2010; ARAÚJO, 2012).

Os estudos de usuários compreendem um campo relevante para a aproximação da oferta de serviços e soluções. Eles possuem a real necessidade dos clientes/usuários da informação nas unidades.

Assim, a temática dos estudos de usuários é um campo consolidado na Ciência da Informação, por isso a aplicação do questionário é o método utilizado com mais frequência. Além disso, a abordagem qualitativa que se apresenta no "Mapa de Empatia" pode ser mais uma forma de coletar dados e informações dos usuários.

O objetivo do presente estudo é apresentar o instrumento "Mapa de Empatia". Este é descrito como uma proposta complementar aos métodos já consolidadas no âmbito dos estudos de usuários, por meio da realização de uma aplicação em unidades de informação.

O Mapa de Empatia é um instrumento consolidado na área de negócios e gestão, juntamente com a aplicação da ferramenta Business Model Canvas, desenvolvida por Osterwalder (2011). 
Embora recente, já tem sido utilizada por inúmeras organizações a nível mundial, conforme comprova o Guia sobre Business Model Canvas, no website Abertura Simples. Esta ferramenta permite identificar diferentes perfis de clientes/usuários através do preenchimento de um quadro com perguntas que sucitam uma reflexão do ponto de vista deste personagem. Para o preechimento deste mapa é necessário trabalhar a empatia, colocando-se no lugar do usuário para tentar entender como pensa e como a realidade em que vive pode influenciar determinados comportamentos. (RESULTADOS DIGITAIS, 2019). Sua aplicação permite identificar mais de um tipo de perfil de usuário, que pode ser caracterizado sob diversos prismas: usuários mais exigentes, novos usuários, usuários assíduos, potenciais usuários, etc.

É relevante destacar que esforços iniciais para a aproximação da ferramenta nos estudos de usuários no âmbito das unidades de informação são evidências nos estudos de Cândido, Bertotti e Bedin (2017); Valdrich e Cândido (2018). Além disso, alguns estudos internacionais sobre esta temática podem ser mencionados. Por exemplo, Lavazza (2016), que prevê a possibilidade de aplicação do Mapa de Empatia em bibliotecas numa abordagem que defende este espaço como uma experiência ao usuário. Os estudos de Banović et al (2016); Beeching (2016). Por fim, citar-se-á Toro-Jarrín, Ponce-Jaramillo e Güemes-Castorena(2016), que apontam as características e o uso do Mapa de Empatia, aproximando da abordagem de resoluções de problemas, a partir de um conjunto de ideias e insights de forma integrada e criativa, chamado Design Thinking.

Os resultados do presente estudo evidenciam que o instrumento "Mapa de Empatia" pode gerar constatações pertinentes na compreensão do comportamento e da realidade do perfil de usuário. Estas informações podem complementar e auxiliar na interpretação e na análise de resultados de um estudo de usuário na íntegra.

\section{ESTUDO DE USUÁRIOS DA INFORMAÇÃO}

A informação tem sido considerada um ativo estratégico para os processos das organizações. Isto porque, quem a detém e sabe, estrategicamente utilizá-la, possui grande chance de obter êxito frente aos concorrentes. A característica peculiar de possuir custos elevados de produção e baixo custo de reprodução afeiçoa a dinâmica deste mercado, bem como otorna um ativo valioso e um trunfo para análises do ponto de vista financeiro, dos clientes, do produto e do processo, entre outros. 
Quando a informação é um produto final de oferta, podem ser atribuídosvalores diferentes para atender as dimensões consideradas relevantes para cada perfil de cliente/usuário. Shapiro e Varian (1999) elencam as seguintes proporçõesda informação: tempo de espera, interface com o usuário, conveniência de imagem, velocidade de operação, facilidade de uso, capacidade, características e funções, abrangência esuporte.

Estas dimensões se relacionam com as quatro principais características consensuais do valor da informação na área de Ciência da Informação: a) tipo da informação; b) atualidade da informação; c) qualidade da informação; e) governança da informação. (BALTZAN, 2016).

Para que seja possível e viável oferecer diferentes categorias de um mesmo produto de informação, é imprescindível definir os segmentos de clientes. $E$, neste tipo de estratégia, a análise do mercado se torna uma ação crucial no processo. Os autores Shapiro e Varian (1999) citam a necessidade desta distinção do perfil dos clientes no caso das empresas aéreas, diferenciando-se emperfil de negócios versus turista. É importante perceber, por fim, as diferenças no comportamento destes perfis e refletir sobre os atributos básicos para elaborar distintasopções de pacotes.

Portanto, a interação com o cliente/ usuário é uma ação estratégica na oferta de valor das organizações. Por este motivo,estar atento sobre o comportamento e as potenciais alterações pode proporcionar certa vantagem competitiva e, até mesmo, a criação de novos modelos de negócio.

Uma das características marcantes da atual sociedade é a proatividade e o novo perfil dos clientes/usuários, abordagem percebida, também, nas eras mais atuais da Gestão da Qualidade, ao inserir a visão do usuário, por exemplo. Uma das explicações deste comportamento se deve ao maior acesso aos recursos informacionais e àfacilidade na interação com usuários e potenciais usuários.

$O$ uso estratégico deste tipo de informação permite que a oferta de serviço seja próxima do perfil e do comportamento do usuário. Por exemplo, há informações que podem identificar usuários/clientes que estejam dispostos a pagar mais por buscas de informação mais avançadas e que possam atender a sua necessidade estratégica. (SHAPIRO; VARIAN, 1999).

É possível afirmar, também, que o novo perfil do cliente/usuário é mais exigente no que diz respeito a sua experiência com produtos e serviços dos quais faz uso. Isto implica a necessidade de novas análises e a adoção de estratégias 
que possam satisfazer as necessidades dos clientes/usuários. O desafio da interação com os clientes/usuários é marcado pela forte concorrência, característica evidente do atual cenário. Em contraste, os canais de interação estão mais acessíveis devido aos desenvolvimentos tecnológicos, que permitem aproximar pessoas e grupos dispersos geograficamente.

O campo de pesquisa dos estudos de usuário é uma aplicação consolidada na literatura da Ciência da Informação. Uma busca rápida permite observar a quantidade e a diversidade de contextos dos estudos empíricos já realizados.

Os primeiros estudos que procuraram entender as necessidades de informação e o uso de serviços em unidade de informação remontam o ano de 1948. Nesta época, as pesquisas foram conduzidas por bibliotecários e gestores para o planejamento dos serviços, na ocasião da Conferência, sobre Informação Científica da Royal Society. (CHOO, 2003). Apesar disso, apenas na década de 1960 ocorreu o desenvolvimento de um número maior deste tipo de estudo.

É importante mencionar que as características destes estudos evoluíram, ao longo dos anos, no que se refere àsdiferentes abordagens na interpretação e na forma de conduzir os estudos de usuários. Até a década de 1960, os estudos de usuários centravam a sua análise sob o ponto de vista do uso dos sistemas de informação, por isso esta era considerada uma abordagem tradicional.

A partir da década de 1970, ocorre uma alteração na forma de analisar estas informações, chamada de abordagem alternativa ou da percepção, na qual a ênfase decorre sob a ótica do usuário. São destaques da abordagem alternativa a contribuição de Taylor (1982) sobre o valor agregado da informação, o processo construtivista de Kuhlthau (1991) e a abordagem sense-making, de Devin e Nilan (1986). Portanto, os estudos mais recentes de usuários seguem essa abordagem alternativa, centrando-se no perfil dos usuários. Isso porque, tais carências são fatores considerados chave para a obtenção de conteúdo que permita definir proposta de novos serviços e, até mesmo, a reformulação de serviços em vigor.

Os estudos de usuários podem utilizar métodos de abordagem quantitativa, qualitativa e, também, uma combinação de destas naturezas. Nas palavras de Baptista e Cunha (2007, p. 169) sobre os objetivos dos usuários na aplicação dos estudos: "parece que permanecem imutáveis, quais sejam: coletar dados para criar e/ou avaliar produtos e serviços informacionais, bem como entender melhor o fluxo da transferência de informação". 
O estudo de Araújo (2013) apresenta em seu estudo o termo "sujeito informacional" indicando a necessidade de análise a partir de duas dimensões: sujeitos (seres humanos) e informação. O exercício de aplicação, realizado neste estudo, constrasta com a necessidade de compreensão sobre o sujeito informacional. Esta é, deste modo, uma abordagem interdisciplinar, que utiliza um instrumento de gestão e negócios, na análise do comportamento e do perfil dos usuários.

Ao longo dos últimos anos, alguns estudos sobre 0 comportamento dos usuários utilizaram, também, a ferramenta "Gestão de Relacionamento com o Cliente" (CRM, em inglês: Customer Relationship Management). Seu objetivo era propor uma integração dos estudos de usuários em unidades de informação, como é o caso de Souza, Neves e Lucas (2005) que pesquisam sobre a aplicação de CRM nas estratégias de bibliotecas universitárias; Molina (2001) utiliza a ferramenta CRM nos serviços das bibliotecas como negócios na nova economia; Finger e Castro (2004) falam sobre a nova gestão de bibliotecas universitárias com a implementação de CRM; Lima e Carvalho (2013) abordam o CRM enquanto nova abordagem de gestão estratégica em bibliotecas universitárias.

Entre os métodos consolidados nos estudos de usuários, destacam-se: questionários, entrevistas, técnica de Delfos (Delphi), observação, análise de conteúdo, etc. Porém, a maioria dos estudos de usuários centra-se no uso do questionário como método de aplicação seguido da aplicação de entrevistas. (BAPTISTA; CUNHA, 2007). Embora sejam métodos bastante tradicionais e consolidados, existe espaço para novas propostas e, também, de aplicações complementares para a aproximação e análise dos usuários, como é o caso da ferramenta apresentada a seguir - Mapa de Empatia.

\section{MAPA DE EMPATIA}

O Mapa de Empatia é um instrumento utilizado para entender as necessidades dos clientes/usuários. O termo é sintetizado em uma matéria da empresa Resultados Digitais (2019) sobre este sentimento, como "descreve a habilidade de compreender o estado emocional do outro ao colocar-se no lugar dele" permite, ainda, ver situações sob perspectivas diferentes e entender as razões pelas quais indivíduos agem de determinada forma, evitando embates desnecessários. Em outras palavras, empatia significa se colocar no lugar do outro e este é o ponto central do instrumento para que se 
possa conhecer melhor a realidade do usuário. Um dos questionamentos em voga na aplicação deste instrumento é definir “qual é a dor da pessoa(persona)?".identificando a persona, neste contexto, como o usuário/cliente. O exercício de se colocar no lugar do outro pode proporcionar à instituição novos insights para definição da estratégia e oferta de futuros produtos/serviços, da mesma forma em uma unidade de informação, no que tange à identificação das necessidades informacionais.

Até o momento, este instrumento tem sido utilizado, sobretudo, na análise de negócios que estejam em fase inicial ou de reestruturação. Ele permite conhecer o perfil dos clientes para que seja possível ofertar algo que apresente valor agregado.

Um dos grandes precursores do Mapa de Empatia foi Alexander Osterwalder (2011), que introduziu uma proposta dinâmica de ferramentas associadas ao Business Model Canvas que, o qual permite traçar, de forma simples e prática, a proposta de valor das organizações. Este tipo de ferramenta pode ser usado de maneira conjunta e complementar ao Mapa de Empatia, pois analisará as dores e os ganhos dos clientes/usuários, enquanto o canvas analisa o negócio como um todo: canais de relacionamento, proposta de valor, parcerias chave, estrutura de custos, receitas, etc.

Este tipo de instrumento traz uma abordagem dinâmica para a construção de novos modelos de negócios, o que tem, atualmente, despertado grande interesse nas empresas startups ${ }^{1}$. Isto porque, no caso destas empresas existe um dinamismo acentuado na maneira de conduzir os processos de gestão e o relacionamento com os stakeholders ${ }^{2}$ envolvidos. Nas unidades de informação, este instrumento permitirá a adoção de um processo de análise visual e dinâmico, que poderá ser repensado com certa periodicidade, de acordo com as definições estratégicas da instituição.

É importante ressaltar, ainda, que o Mapa de Empatia tem um papel interessante na análise da visão do perfil e nas necessidades do usuário/cliente de forma simples e rápida. A forma de pensar sobre o prisma do usuário/cliente permite pensar nas causas e possíveis justificativas de determinados comportamentos e fenômenos que caracterizam a experiência do usuário com 0 produto/serviço ofertado.

\footnotetext{
${ }^{1}$ Empresa com poucos anos que apresenta modelo de negócio passível de ser escalável, com estrutura mais enxuta mas com potencial de mercado.

2 Todos os atores envolvidos em determinado processo/contexto: bibliotecários, professores, usuários, potenciais usuários, etc.
} 
Embora o Mapa de Empatia seja mais utilizado no ambiente de negócios, algumas abordagens distintas incorporam 0 instrumento em ambientes didáticos, enquanto uma autoavaliação docente. Neste caso, o professor utiliza o mapa para definir o perfil dos alunos e, assim, a possibilidade de propor ações didáticas bem como a organização das aulas para atender às necessidades específicas da turma. (GIRON, 2017).

No contexto dos estudos de usuários, a aplicação do Mapa de Empatia se caracterizaria como uma abordagem qualitativa. Esse mapa, associado a outros métodos, poderia ser um exercício de identificação das necessidades e demandas dos usuários.

É importante mencionar que a proposta de utilização do instrumento pode ser adaptada e implementada de maneira personalizada, ao longo das futuras aplicações, para atender os estudos de usuários das unidades de informação.

Figura 1 - Mapa de Empatia

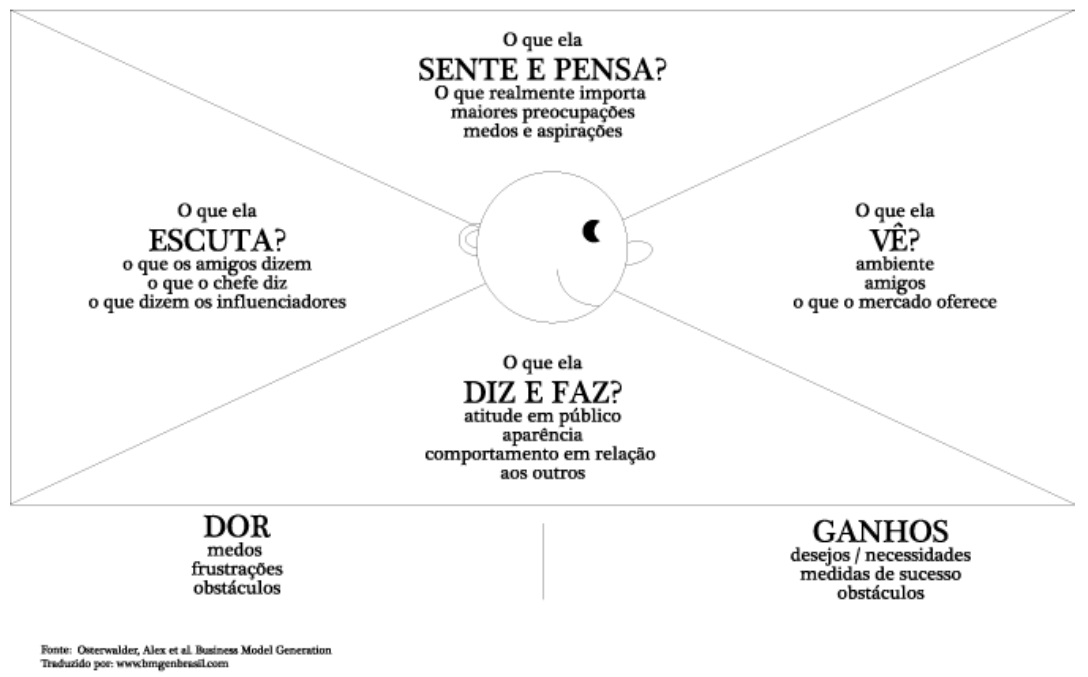

FONTE: Extraído de NAKAGAWA (2001).

O preenchimento dos campos do Mapa de Empatia corresponde às informações relativas ao perfil geral do usuário/cliente. Foi realizado por meio da identificação de suas necessidades, receios e sensações, que podem ser percebidas pelo que 0 ambiente externo apresenta. Sendo esta uma visão geral e não individual, é possível 
traçar mais de um Mapa de Empatia, seguindo diferentes perfis de usuários/clientes. Estas informações foram baseadas na percepção dos estagiários das unidades de informação, que interagem diretamente e diariamente com os usuários.

A seguir,serão elencados os campos de preenchimento do Mapa de Empatia:

- Dor: Neste campo devem ser identificados os receios, frustações e obstáculos percebidos pelo usuário na sua experiência de uso. São os fatores que podem interferir em uma boa experiência do usuário no contexto analisado, bem como entender estes fatores de forma a identificar os que estejam diretamente relacionados à proposta de oferta que o usuário/cliente recebe. Além disso, deve-se questionar sobre os que envolvem outros stakeholders e/ou demandam ações que não correspondem com o core (negócio central) da organização.

- Ganhos: Este campo deve ser preenchido com as necessidades e desejos dos usuários e os obstáculos que pretende ultrapassar. Através destas respostas, se percebe o que motiva o usuário e, assim, é possível analisar o seu comportamento de forma mais próxima e, muitas vezes, como explicação para determinadas ações e reações que apresenta.

- O que sente e pensa? São informações relacionadas diretamente às emoções dos usuários, o que sente e o que pensa em relação as suas necessidades e o que está sendo oferecido. Uma relação entre expectativa e realidade, sob o ponto de vista dos usuários.

- O que vê? Neste campo são identificadas todas as referências e influências visuais que possam interferir no comportamento do usuário.

- O que escuta? Neste caso não apenas as coisas que o usuário escuta no seu ambiente ou em outros ambientes em que tenha acesso, mas também o entendimento de quem ele escuta. Ou seja, quem é ou poderá ser um influenciador deste perfil de usuário.

- O que diz e faz? No momento em que compra ou faz uso de determinado serviço, quais são os aspectos que caracterizam a experiência do usuário, desde a tomada de decisão até uma ação final futura. Este campo permite analisar as atitudes e falas do usuário, além de verificar a coerência nestas ações. É possível, também, determinar os padrões de comportamento para cada fase de experiência do usuário, em determinado serviço. (RESULTADOS DIGITAIS, 2019). 


\section{PROCEDIMENTOS METODOLÓGICOS}

A presente pesquisa caracteriza-se como exploratória, ao analisar a proposta de um instrumento como abordagem complementar às ferramentas já consolisadas no âmbito dos estudos de usuários. Caracteriza-se como uma pesquisa empírica, ao verificar usuários de unidades de informação.

O exercício de aplicação do Mapa de Empatia foi realizado juntamente com alunos da disciplina "Estudos de Usuário da Informação" ${ }^{3}$, referente à unidade de informação na qual aplicariam o trabalho de avaliação. Os 18 alunos da turma receberam instruções sobre a aplicação em sala de aula, de forma expositiva e dialogada, tendo sido realizado, nesta oportunidade, um teste hipotético para verificação do entendimento na interpretação das questões a serem respondidas no mapa.

A fase de aplicação do Mapa de Empatia correspondeu à primeira etapa do estudo de usuário com o intuito de fazer uma análise do perfil do principal segmento de usuário atendido na unidade de informação. Posteriormente, foi aplicado um questionário desenvolvido pelos alunos específicos para a unidade de informação que haviam escolhido, em quatro casos. Estes questionários não serão aqui expostos, pois o presente estudo tem como foco a análise sobre a aplicação do Mapa de Empatia.

Neste caso, os resultados obtidos na aplicação do 'Mapa de Empatia' foram importantes para a análise da realidade e identificação de problemas reais e potenciais soluções na unidade de informação.

Para o preenchimento do instrumento 'Mapa de Empatia' foram reunidas equipes de até três pessoas. Uma delas tem contato direto com a instituição e uma pessoa é responsável pela mediação da dinâmica realizada em sala de aula. Ressalta-se, também, que as aplicações deste estudo não ocorreram in loco, pois se tratando, ainda, de uma fase inicial de aproximação do Mapa de Empatia com os Estudos de Usuários, optou-se por trabalhar em sala de aula com alunos estagiários de duas unidades de informação.

$\mathrm{Na}$ aplicação do instrumento, os alunos receberam recomendações de preenchimento durante a aula expositiva e dialogada. Entre estas recomendações, destaca-se o uso de post-its para que seja fácil e flexível a realização de eventuais alterações, bem como a reunião da equipe em volta do mapa e de preferência

${ }^{3}$ Curso de Graduação em Arquivologia 
todos de pé. Para a apresentação dos resultados no documento, as informações foram disponibilizadas por meio de um template da ferramenta ${ }^{4}$, conforme se apresenta nas Figuras 2 e 3.

\section{MAPA DE EMPATIA NOS ESTUDOS DE USUÁRIOS DA INFORMAÇÃO}

A presente seção descreve a aplicação do "Mapa de Empatia", bem como a realização de uma análise sobre como esta pode contribuir para os estudos de usuário, desde a sua interpretação nos resultados. Além disso, será descrito como uma forma dinâmica de interação com os stakeholders envolvidos no processo (usuários, equipe de colaboradores, mediador do estudo).

As Figuras 2 e 3 apresentarão os perfis do principal segmento de usuários de instituições distintas. Na unidade de informação "A", os usuários analisados são colaboradores internos, pois a atividade central do ambiente analisado é o atendimento interno, ou seja, são atividades meio e não atividades finais da instituição.

Figura 2 - Mapa de Empatia em um setor de arquivo - Unidade de Informação 'A'

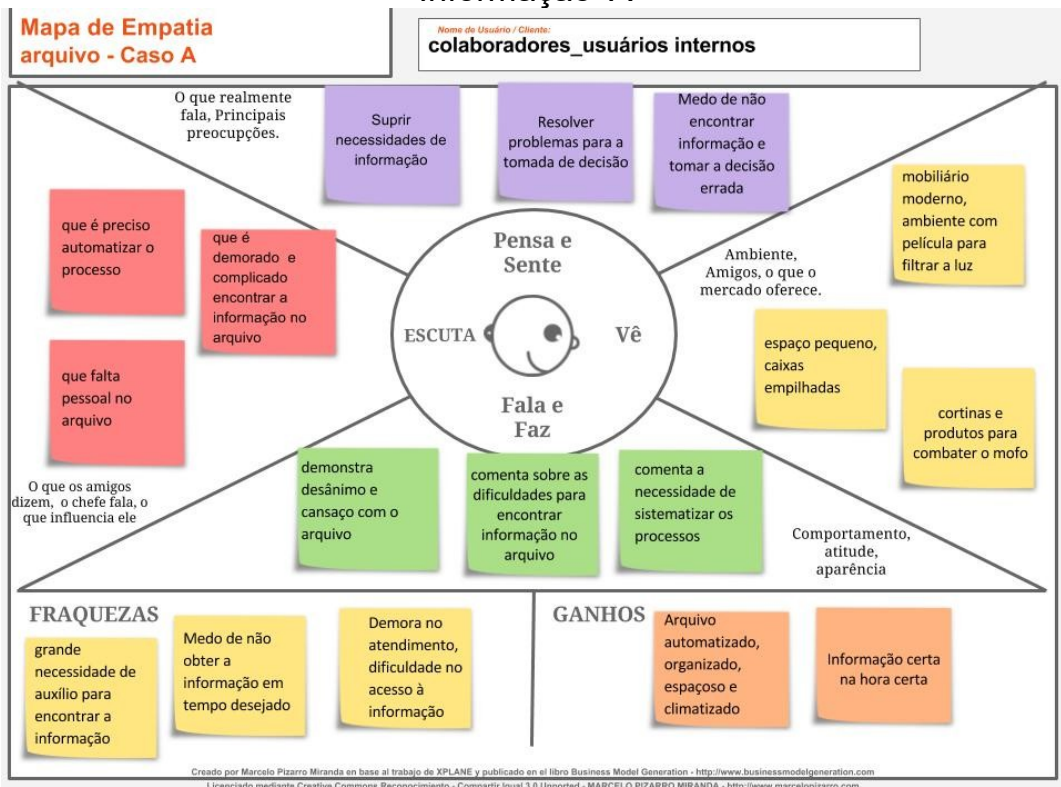

FONTE: Dados da pesquisa

${ }^{4}$ Obtido em: http://info.endeavor.org.br/ferramenta-mapa-empatia 
O segmento de perfil do usuário analisado na unidade de informação ' $A$ ' demonstra a forte necessidade de informação específica para determinado processo associada ao receio de não obter esta informação. Este usuário possui necessidades que, em alguns casos não são possíveis de serem atendidas e, para sanar essas necessidades, são encaminhados para outros órgãos públicos correspondentes, quando é o caso.

Sendo estes usuários internos colaboradores de outros departamentos, esta situação poderá interferir no clima organizacional e, por consequência, gerar uma desvalorização do papel deste departamento. Além disso, corrobora com a importância da análise das dimensões do sujeito informacional e tecnológica, mencionada por Araújo (2013).

É possível observar, a partir da análise do mapa, que este perfil do usuário já apresenta receio no primeiro momento das suas experiências. Isto pois existem ideias pré-estabelecidas sobre como pode correr o processo e eventuais entraves para o alcance do objetivo e da conclusão das suas atividades finais.

Este clima de receio pode tornar a experiência do usuário, ao final do atendimento, bastante satisfatória, caso a sua necessidade seja atendida. Certamente, isso passará uma ideia positiva aos demais colaboradores da instituição e proporcionará um reconhecimento maior do departamento.

$\mathrm{Na}$ unidade de informação 'A', o Mapa de Empatia foi utilizado como primeiro passo associado à aplicação de um questionário de satisfação dos colaboradores internos que já utilizaram os serviços do setor de arquivos da instituição. O instrumento, neste caso, possibilitou definir alguns elementos-chave para o clima organizacional na relação do setor de arquivos com os colaboradores de outros departamentos. Esta identificação do contexto é, também, defendida por Shapiro e Varian (1999), ao abordarem diferentes segmentos e características de perfis de clientes/ usuários.

A unidade de informação 'B' é uma instituição de arquivo, na qual um dos principais segmentos de usuários (finais) são os advogados, conforme apresenta a Figura 3. 
Figura 3 - Mapa de Empatia em um setor de arquivo - Unidade de Informação 'B'

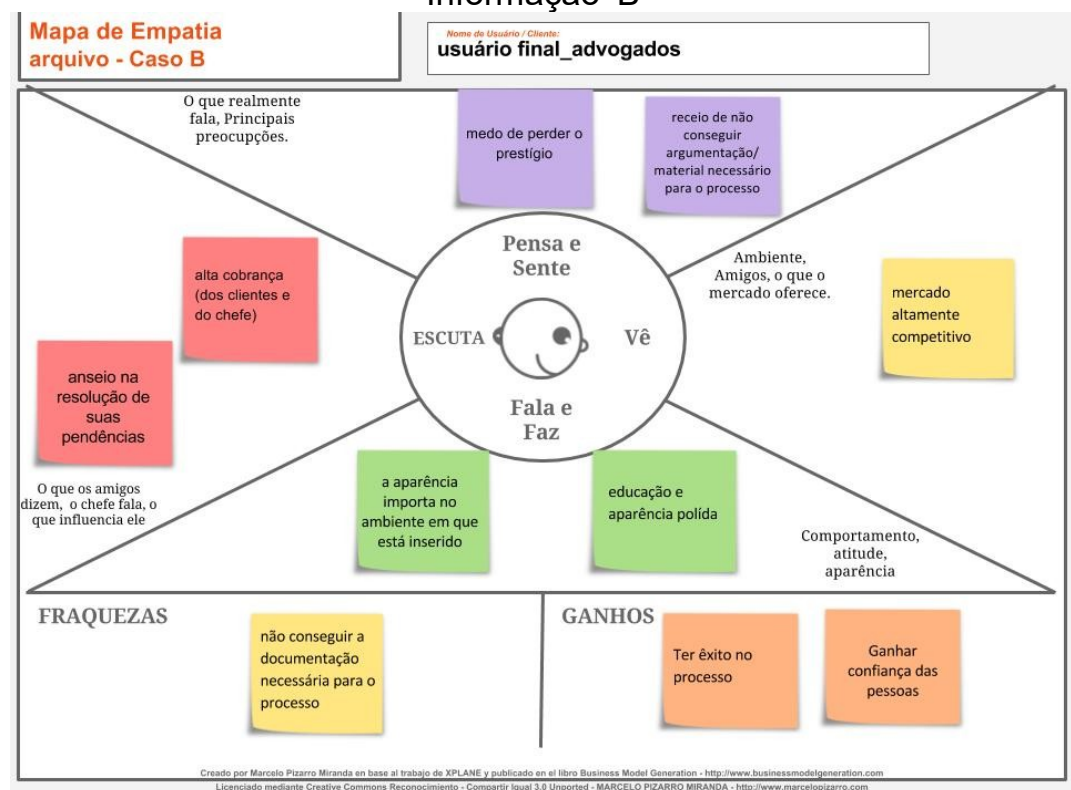

FONTE: Dados da pesquisa

Nesta aplicação, é possível perceber que a necessidade do usuário final, neste caso os advogados, está diretamente relacionada ao atendimento dos seus clientes finais. Por este motivo, a agilidade dos processos no arquivo também permitirá uma entrega final do serviço ágil por parte dos profissionais advogados.

Este perfil de usuário tem uma frequência maior na instituição e acaba por conhecer, mais de perto, os procedimentos pelos quais se precisa passar. Algumas características podem ser evidenciadas neste perfil de usuário: possui expertise em questões jurídicas que se aproximam do trabalho desenvolvido na unidade de informação, podendo ser um potencial stakeholder para contribuir em ideias e sugestões nas eventuais implementações de melhorias. Tendo em consideração que este tipo de usuário está a serviço de seu cliente, a agilidade no processo, isso o favorece de forma mais acentuada, pois, neste caso, o tempo pode ser facilmente sinônimo de dinheiro.

No campo "o que ele escuta", poderão ser utilizadas informações que refletem como a instituição é vista no ambiente externo, quais as ideias pré-estabelecidas emergem e como isto 
pode ser utilizado de forma estratégica pela instituição, na sua interação com a sociedade em geral.

Por fim, utilizando o caso do perfil de usuário observado na unidade de informação 'B', torna-se importante a compreensão sobre determinados comportamentos e atitudes. Esta postura pode ser tratada como aliada nos testes de implementação de atividades organizacionais, por exemplo.

A agilidade nos processos, a implementação de sistemas de gestão da qualidade e as inovações podem ser favorecidas com o apoio dos usuários da unidade de informação. Eles detêm uma experiência e vivência com um olhar diferenciando em relação à experiência dos colaboradores e gestores da unidade de informação.

\section{CONSIDERAÇÕES FINAIS}

Embora os estudos de usuáriosem unidades de informação já possuam mais de 50 anos, desde as primeiras aplicações, é possível perceber que, ao longo das últimas décadas, muitas transformações foram percebidas. Isso ocorreu não só na forma de valorizar os estudos de usuários, mas também na escolha dos métodos e na interpretação dos seus resultados.

Este exercício compreende o início de uma análise sobre a aplicação do Mapa de Empatia para suporte e instrumento complementar de origem qualitativa dosestudos de usuários. Desse modo, é possível, em aplicações futuras, serem apresentadas propostas de alterações que aproximem o potencial do instrumento para informações específicas aos usuários das unidades de informação. Assim, recomenda-se que estas aplicações sejam realizadas com a participação dos profissionais responsáveis e que possuam uma visão sistêmica da instituição.

O Mapa de Empatia é apresentado neste estudo como mais um método a ser utilizado no âmbito das investigações de usuários que permitam uma abordagem mais visual e dinâmica. Da mesma forma como o CRM tem sido utilizado, o Mapa de Empatia pode auxiliar e enriquecer os estudos empíricos neste campo do conhecimento e, consequentemente, para a Ciência da Informação.

Entretanto, algumas limitações podem ser elencadas na aplicação apresentada neste estudo e que a partir da evolução desta proposta podem ser facilmente ultrapassadas em futuras aplicações do instrumento: a primeira observação é sobre o fato 
da aplicação não ter ocorrido in loco, permitindo assim a participação de um número maior de pessoas envolvidas e conhecedoras da realidade em causa. Também poderiam ser convidados representantes: clientes/usuários, potenciais usuários, fornecedores, etc.

Ressalta-se que as aplicações deste estudo não ocorreram com base nas experiências dos estudantes no campo de estágio, pois, tratando-se, ainda, de uma fase inicial de aproximação do Mapa de Empatia com os Estudos de Usuários, optou-se por trabalhar em sala de aula, com alunos estagiários destes locais.

Espera-se que, a partir deste estudoque se caracteriza como exploratório, possam ser realizadas pesquisa empíricas futuras. Nesta oportunidade, encorajam-se estudos subsequentes que possam abordar de forma empírica o uso e adequação do Mapa de Empatia em outros contextos, bem como análises comparativas com outros métodos já consolidados nos estudos de usuários.

\section{REFERÊNCIAS}

ABERTURA SIMPLES. Guia: Tudo que você precisa saber sobre o Business Model Canvas. Disponível em: https://aberturasimples.com.br/ business-model-canvas/. Acesso em 27 de setembro de 2019.

ARAÚJJ, C. A. Á. Paradigma social nos estudos de usuários da informação: abordagem interacionista. Informação \& Sociedade: Estudos, João Pessoa, v. 22, n. 1, p. 145-159, 2012. Disponível em: http://hdl.handle.net/ 20.500.11959/brapci/91416. Acesso em: 28 set. 2019.

ARAÚJO, C. A. Á. O sujeito informacional no cruzamento da ciência da informação com as ciências humanas e sociais. XIV ENCONTRO NACIONAL DE PESQUISA EM CIÊNCIA DA INFORMAÇÃO (ENANCIB 2013) GT 3: Mediação, Circulação e Apropriação da Informação. João Pessoa: 2013. Disponível em: http://www.brapci.inf.br/index.php/article/ download/40403. Acesso em: 28 set. 2019.

BALTZAN, P. Tecnologia orientada para gestão. Porto Alegre: AMGH, 2016.

BANOVIĆ, M.; KRYSTALLIS, A.; GUERRERO, L.; REINDERS, M.J. Consumers as co-creators of new product ideas: An application of projective and creative research techniques. Food Research International, v. 87, p. 211-223, 2016. https://www.sciencedirect.com/science/article/abs/pii/ S0963996916302861. Acesso em: 28 set. 2019. DOI: https://doi.org/10. 1016/j.foodres.2016.07.010 
BAPTISTA, S.G., CUNHA, M.B. Estudo de usuários: visão global dos métodos de coleta de dados. Perspectivas em Ciência da Informação, v. 12, n. 2, p. 168-184, 2007. http://www.scielo.br/pdf/pci/v12n2/v12n2a11. pdf. Acessoem: 28 set. 2019.

BEECHING, A. M. Who is audience? Arts \& Humanities in Higher Education, v. 15, (3-4), p. 395-400, 2016. https://journals.sagepub.com/doi/ 10.1177/1474022216647390. Acesso em: 28 set. 2019. DOI: https://doi.org/ $10.1177 \% 2 \mathrm{~F} 1474022216647390$

CÂNDIDO, A. C.; BERTOTTI, P. S. S.; BEDIN, J. O potencial das ferramentas atuais de gestão \& negócios aplicados às unidades de informação. Revista Brasileira de Biblioteconomia e Documentação, v. 13, p. 1165-1182, 2017. Disponível em: http://hdl.handle.net/20.500.11959/ brapci/4573. Acesso em: 28 set. 2019.

$\mathrm{CHOO}$, A. Organização do Conhecimento: como as organizações usam a informação para criar significado, construir conhecimento e tomar decisões. São Paulo: Editora Senac, 2003.

COSTA, L.F., RAMALHO, F.A. Novas Perspectivas dos Estudos de Satisfação dos Usuários. Encontros Bibli: Revista Eletrônica de Biblioteconomia e Ciência da Informação, v. 15, n. 30, p. 57-73, 2010. Disponível em: https://periodicos.ufsc.br/index.php/eb/article/view/15182924.2010v15n30p57/19530. Acesso em: 28 set. 2019. DOI: https://doi.org/10.5007/1518-2924.2010v15n30p57

DERVIN, B., NILAN, M. Information needs and uses. Annual Review of Information Science and Technology, v. 21, p. 3-33, 1986.

FIGUEIREDO, N. Estudos de uso e usuários da informação. Brasília: Ibict, 1994.

FINGER, A. B., CASTRO, G. Mudança na gestão das bibliotecas universitárias públicas através da implementação do Customer Relationship Management (CRM). In: SEMINÁRIO NACIONAL DE BIBLIOTECAS UNIVERSITÁRIAS, Anais do Seminário Nacional de Bibliotecas Universitárias, n. 13, Natal, 2004.

GASQUE, K.C.G.D., COSTA, S.M.S. Evolução teórico-metodológica dos estudos de comportamento informacional de usuários. Ciência da Informação, Brasília, v. 39, n. 1, p. 21-32, 2010. http://www.scielo.br/pdf/ci/ v39n1/v39n1a02. Acesso em: 28 set. 2019.

GIRON, V. Mapa de Empatia Como Instrumento de Autoavaliação Docente. Geekie. São Paulo, 15 março 2017. Disponível em: http://info.geekie.com.br/mapa-da-empatia/. Acesso em 27 de março de 2017.

KUHLTHAU, C.C. Inside the search process: information seeking from the user's perspective. Journal of the American Society for Information Science, v. 42, n. 5, p. 361-371, 1991. http://bogliolo.eci.ufmg.br/downloads/ kuhlthau.pdf. Acesso em: 28 set. 2019. 
LAVAZZA, M.C. La biblioteca come prodotto, come servizio, come esperienza. Bibliotime: Rivista Elettronica per le biblioteche. v. 19, n. 1 (1), 2016. Disponível em: http://www.aib.it/aib/sezioni/emr/bibtime/num-xix1/lavazza.htm. Acesso em 10 de agosto de 2017.

LIMA, L. F., CARVALHO, R.A. O CRM no contexto das bibliotecas universitárias públicas. In: XXV CONGRESSO BRASILEIRO DE BIBLIOTECONOMIA, DOCUMENTAÇÃO E CIÊNCIA DA INFORMAÇÃO. Florianópolis, SC, Brasil, 07 a 10 de julho de 2013. https://portal.febab.org. br/anais/article/view/1421/1422. Acesso em: 28 set. 2019.

MOLINA, C.E.G. CRM (Customer Relationship Management) y Servicios de Información: la biblioteca como un negocio de la nueva economía. Biblios Revista Electrónica de Ciencias de la Información, ano 3, n. 10, 2001. https://www.redalyc.org/articulo.oa?id=16110302

NAKAGAWA, M. Mapa de Empatia para Empreendedores. Endeavor. 2001. Disponível em: http://info.endeavor.org.br/ferramenta-mapa-empatia. Acesso: em 05 de fev. 2017.

OSTERWALDER, A. Business Model Generation - Inovação em Modelos de Negócios: um manual para visionários, inovadores e revolucionários. Rio de Janeiro, RJ: Alta Books, 2011.

RESULTADOS DIGITAIS. Mapa de Empatia: o que é e 6 passos para criar um de qualidade. Disponível em: https://resultados digitais.com.br/ blog/mapa-da-empatia/. Acesso em 27 de setembro de 2019.

SHAPIRO, C., VARIAN, H.R. A economia da informação: como os princípios econômicos se aplicam à era da internet. Tradução: Inojoso, R. Rio de Janeiro: Elsevier, 1999.

SOUZA, N.A., NEVES, G.L.C.,LUCAS, E.O. Estratégia de CRM aplicada a DSI: uma proposta para Bibliotecas Universitárias.. In: VI CINFORM ENCONTRO NACIONAL DE CIÊNCIA DA INFORMAÇÃO, 2005, Salvador. Anais do VI CINFORM. Salvador: UFBA, 2005. http://www.cinformanteriores.ufba.br/vi_anais/docs/NicoleGuilhermeElaineCRM.pdf. Acesso em: 28 de set. 2019.

TAYLOR, R.S. Value-added process in the information life cycle. Journal of the American Society of Information Science, v. 33, n. 5, p. 341-346, 1982. https://asistdl.onlinelibrary.wiley.com/doi/abs/10.1002/asi.4630330517. Acesso em: 28 set. 2019. DOI: https://doi.org/10.1002/asi.4630330517

TORO-JARRÍN, M.A.T.; PONCE-JARAMILLO, I.E.; GÜEMES-CASTORENA, D. Methodology for the of building process integration of Business Model Canvas and Technological Roadmap. Technological Forecasting and Social Change, v. 110, p. 213-225, 2016. https://papers.ssrn.com/sol3/ papers.cfm?abstract_id=2738009. Acesso em: 28 set. 2019. 
VALDRICH, T.; CÂNDIDO, A. C. Mapa de empatia como proposta de instrumento em estudos de usuários: aplicação realizada na biblioteca pública de santa catarina. Revista ACB: Biblioteconomia em Santa Catarina, v. 23, n. 1, p. 107-124, 2018. Disponível em: http://hdl.handle.net/ 20.500.11959/brapci/62482. Acesso em: 28 set. 2019.

WILSON, T.D. Human information behavior. Informing Science Research, v. 3, n. 2, p. 49-55, 2000.http://inform.nu/Articles/Vol3/v3n2p49-56.pdf. Acesso em: 28 set. 2019.

Recebido em: 31/07/2018

Aceito em: 20/03/2019 